\title{
Polya's Problem Solving Strategy in Trigonometry: An Analysis of Students' Difficulties in Problem Solving
}

\author{
Dwi Sulistyaningsih ${ }^{1, *}$, Eko Andy Purnomo ${ }^{1}$, Purnomo ${ }^{2}$ \\ ${ }^{1}$ Department of Mathematics Education, Mathematics and Natural Science Faculty, Universitas Muhammadiyah Semarang, Semarang, \\ Indonesia \\ ${ }^{2}$ Department of Mechanical Engineering, Engineering Faculty, Universitas Muhammadiyah Semarang, Semarang, Indonesia
}

Received December 20, 2020; Revised February 19, 2021; Accepted March 12, 2021

\section{Cite This Paper in the following Citation Styles}

(a): [1] Dwi Sulistyaningsih, Eko Andy Purnomo, Purnomo, "Polya's Problem Solving Strategy in Trigonometry: An Analysis of Students' Difficulties in Problem Solving," Mathematics and Statistics, Vol. 9, No. 2, pp. 127 - 134, 2021. DOI: 10.13189/ms.2021.090206.

(b): Dwi Sulistyaningsih, Eko Andy Purnomo, Purnomo (2021). Polya's Problem Solving Strategy in Trigonometry: An Analysis of Students' Difficulties in Problem Solving. Mathematics and Statistics, 9(2), 127 - 134. DOI: 10.13189/ms.2021.090206.

Copyright $\bigcirc 2021$ by authors, all rights reserved. Authors agree that this article remains permanently open access under the terms of the Creative Commons Attribution License 4.0 International License

\begin{abstract}
This study is focused on investigating errors made by students and the various causal factors in working on trigonometry problems by applying sine and cosine rules. Samples were taken randomly from high school students. Data were collected in two ways, namely a written test that was referred to Polya's strategy and interviews with students who made mistakes. Students' errors were analyzed with the Newman concept. The results show that all types of errors occurred with a distribution of 3.83, 19.15, 24.74, 24.89 and $27.39 \%$ for reading errors (RE), comprehension error (CE), transformation errors (TE), process skill errors (PSE), and encoding errors (EE), respectively. The RE, CE, TE, PSE, and $\mathrm{EE}$ are marked by errors in reading symbols or important information, misunderstanding information and not understanding what is known and questioned, cannot change problems into mathematical models and also incorrectly use signs in arithmetic operations, student inaccuracies in the process of answering and also their lack of understanding in fraction operations, and the inability to deduce answers, respectively. An anomaly occurs because it turns out students who have medium trigonometry achievements make more mistakes than students who have low achievement.
\end{abstract}

Keywords Trigonometry, Sine, Error, Problem Solving

\section{Introduction}

Problem-solving ability is one of the most important math skills for students because it can encourage students to answer the questions themselves. Students become skilled in selecting and identifying relevant conditions and concepts, looking for generalizations, formulating settlement plans, and organizing the skills they have previously had. Many students complain and think that mathematics is a subject that is too difficult that can evoke negative emotions. Many of them feel difficult in solving various mathematical problems such as understanding questions and information provided for problem-solving, use of concepts, calculations, and inaccuracies [1-3]. The psychological impact is the emergence of mathematical anxiety that is accompanied by negative emotions and cognitive so that they are not confident to excel.

Trigonometry is one of the materials studied not only in universities but also in high schools. Trigonometry is an important math lesson because it can improve a variety of cognitive skills in students and has a wide area of use in everyday life. Trigonometry is also a transition from algebra to geometry. Apart from that, trigonometric functions and properties are used in many materials including limits, derivatives, integrals, etc. Trigonometry is the mathematics branch concerned with the relationship involving lengths and angles. Trigonometric functions focus on discussing cyclic phenomena in various applications of trigonometry in fields, especially with 
regard to applications in the field of mechanical and electrical technology. Trigonometry is a basic concept that is very important in mathematics. In many other topics, including algebra, geometry, and graphic concepts, trigonometry is often used as a fundamental principle [4,5]. A strong understanding of trigonometry can enhance the cognitive abilities of students, like critical thinking via the reasoning process and proofing skills [1]. Therefore, solving problems in trigonometry that are considered very difficult by students and teacher candidates [6-7] is very important.

In the last decade, it has been reported by several studies $[8,9]$ that students often experience misunderstandings so they make errors in addressing trigonometric issues. On the other hand, those errors also occur because they cannot develop the concept of trigonometry [9]. Usman and Hussaini [10] reported that in solving trigonometric problems, more than $75 \%$ of students (a total sample of 80 students) undergo errors in transformation errors as well as process skills errors.

Many studies [11,12] have reported that students understand sines and cosines in three ways namely (i) as the point-to-circle coordinates, (ii) as a coordinate of horizontal and vertical line, and (iii) as the ratio of the triangle sides. Trigonometric problem solving is strongly influenced by the stages chosen by students [13]. Students must follow steps such as requiring stages such as identifying and defining problems, exploring solutions, based on strategies, and evaluating. It is really very essential for teachers to see how the trigonometric problems are solved by students.

There have been many studies aimed at improving trigonometric learning [14-16]. However, the difficulty of trigonometry requires teachers to develop positive attitudes in students towards their learning. Therefore, teachers must develop relationships between them in learning so that they can use more effective strategies in order to improve student achievement by enhancing the ability to solve trigonometric problems. This work aims to evaluate students' errors in trigonometry learning with a center of attention on identification the students' errors and their causal factors in solving trigonometric problems with reference to Newman's error analysis. Problem-solving by students uses techniques developed by Polya [17].

\section{Method}

\subsection{Population and Sample}

This study is descriptive through a qualitative approach. The population is 393 students who are distributed in 12 classes in grade XI of State Senior High Schools in Semarang City, Central Java, Indonesia. A sample of 63 students was taken randomly in two different classes.
Before being tested, the samples were grouped based on their achievements in trigonometry namely low, medium, and high.

\subsection{Instrument}

This study applies two instruments which include (1) a question sheet that has been validated by two trigonometry experts and (2) a teacher and student interview guide. The written test instrument consists of four items test to determine the ability to solve problems with the form of description that has been adapted to the assessment standards 'Trends in International Mathematics and Science Study (TIMSS)'. There are some questions in the interview regarding the rasons of mistakes made in figure out item tests by learners.

Two trigonometry experts validated the test question construction to determine the level of capacity of the test for the problem solving aspect [18]. The four test items specified are subjective questions and contain the elements of problem-solving. The items tested on the sample are as follows.

1. Sinta, Desi, and Mawar are playing in the schoolyard, and their positions form a triangle. If the distance between Sinta and Desi is $8 \mathrm{~m}$, the angle formed by the position of Sinta, Mawar, and Desi is $45^{\circ}$ and the angle formed by the Sinta, Desi and Mawar position is $60^{\circ}$. Determine the distance between Sinta and Mawar!

2. A fishing boat set sail to the west as far as $80 \mathrm{~km}$. The ship continued its journey by changing direction $30^{\circ}$ to the south for $60 \mathrm{~km}$. Determine the existing ship distance with the position when the ship first departed.

3. A piece of land in the form of a parallelogram with a longer side is $12 \mathrm{~m}$ and the shorter side is $10 \mathrm{~m}$. If the longer diagonal is $14 \mathrm{~m}$, find the angle formed by the shorter side and the shorter diagonal.

4. Ali and Beta were assigned to raise the flag to a pole. They are in a straight line with the flagpole, with the distance of each student to the flagpole is $1 \mathrm{~m}$ and the depression angle of the top of the flagpole to students' shoes is $30^{\circ}$. Determine the distance of the top of the flag pole to the student's shoes.

Test items that have been declared valid are tested on samples with a duration of 25 mins. Student errors in working on test problems were analyzed based on the Newman concept [19] which divides errors into five types, namely RE, CE, TE, PSE, and EE.

\subsection{Data Collection}

Data were collected by two techniques i.e., written tests according to Polya's strategy [17] and interviews that were used to measure students' abilities and to determine errors in solving trigonometric problems, respectively. The test 
instrument consists of four items test to determine the ability to solve problems with the form of description that has been adapted to the assessment standards TIMSS. There are some questions in the interview with reference to the factors that lead to mistakes in find an answer the item test.

\subsection{Data Analysis}

Qualitative analyses are used to explain students' errors in problem-solving based on the Newman theory of errors [19]. Newman error indicators are based on Elsa [20].

\subsection{Reliability and Validity}

To ensure that the data is credible, observations are made more closely and continuously. In addition, interviews were also conducted with students through more detailed and repeated questions. High data validity was obtained through written tests whose results were compared with the results of interviews with students. Transferability is carried out by describing and describing in a detailed, clear, and systematic way to the type of student error both for written tests and interviews based on Newman's theory.

\section{Results}

\subsection{Student Test Data}

All test problems have been done by students using Polya's strategy. Students who answered the questions correctly, wrong, and did not answer were $72(28.2 \%)$, $168(66.6 \%)$, and $12(4.8 \%)$, respectively. The distribution of student answers for each test item is presented in Figure 1. About $60 \%$ of students did not answer item test 4 which indicates that this test item is considered the most difficult by students. This condition is inversely proportional to item test 1 where none of them did not do it.

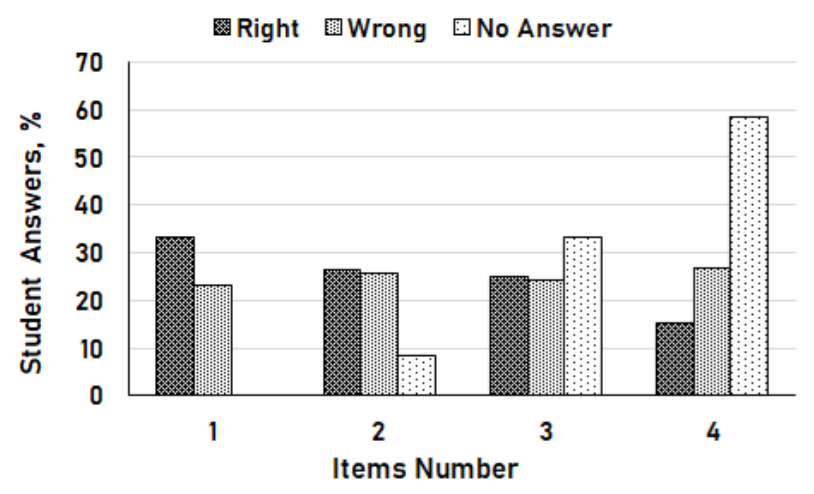

Figure 1. Student answers on each test item

The error level of student answers that have been analyzed using the Newman method is $21.21,23.86,23.71$, and $31.22 \%$ for the answer items test numbers $1,2,3$, and
4, respectively. The error distribution based on its type is $3.83,19.15,24.74,24.89$ and $27.39 \%$ for reading error (RE), comprehension error (CE), transformation error (TE), process skills error (PSE), and encoding error (EE), respectively. The number of errors for each test item on different errors type are shown in Figure 2.

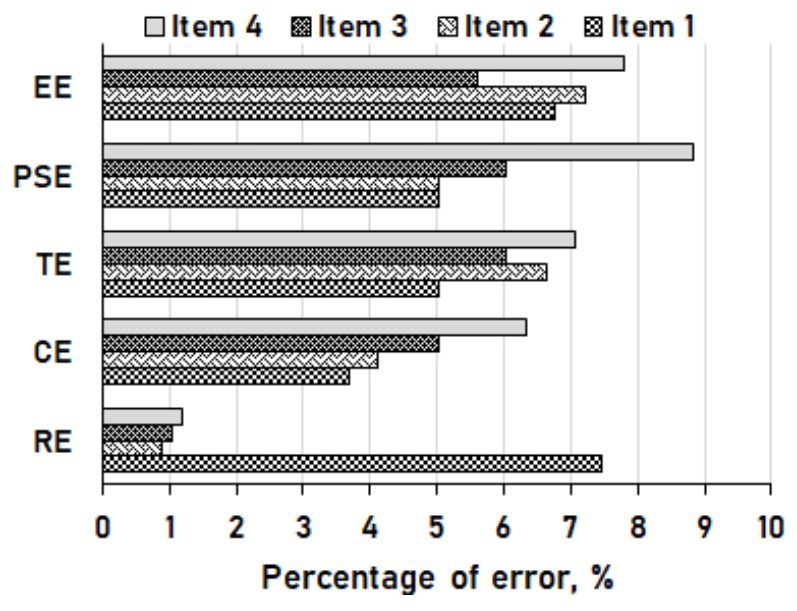

Figure 2. The percentage of error for each test item analyzed is based on Newman theory

\subsection{Analysis for Reading Error}

A total of $70.74 \%$ RE occurs when students work on item 1 (Figure 2). The RE occur in reading symbols or important information in the problem. This error is characterized by the inability of students to solve problems in accordance with the demands of the problem so that student work is not right [21]. This reason is confirmed by the results of the interview with students (St.5) as follows.

$T e$ : In your opinion, is question number 4 included in the easy, medium or difficult category?

St.5 : It's very difficult, $\mathrm{Mr}$

Te : Which part do you find difficult?

St.5 : I don't know what is meant by the angle of depression.

Te : Have you ever heard that term?

St.5 : Yes, I am, but I'm still confused about distinguishing some other terms.

Te : What do you think was questioned in item 4 ?

St.5 : I am so sorry, I think the distance of the flagpole to students.

The dialog shows that students misread the question so that what students answer is the distance of the flagpole to students, not the distance of the peak of the flagpole to students. In addition, students also cannot interpret mathematical terms correctly. The term depression angle in the problem is understood by students as an elevation angle so that the placement of angles in the picture is 
wrong. This error occurs because of the inaccuracy and rush of students in reading the questions so that their work does not match the test questions. Examples of student work errors due to reading errors are shown in Figure 3.

4. Given that: The distance of the student to the pole is $1 \mathrm{~m}$ Depression angle of the top of the flagpole to students' shoes is $30^{\circ}$

Asked : distance from the pole to the student's shoe? Solution :

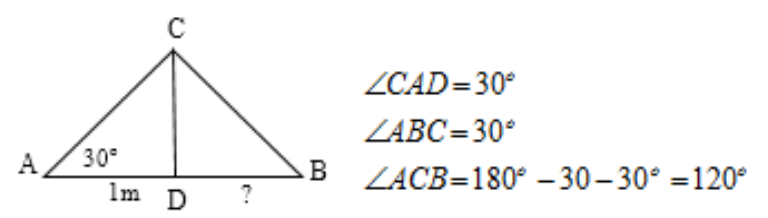

by using the sin rule:

$$
\begin{array}{l|l}
\frac{B D}{\sin \angle B C D}=\frac{C D}{\sin \angle C B D} & B D=\frac{1 / 2 \sqrt{3} C D}{1 / 2} \\
\frac{B D}{\sin 60}=\frac{C D}{\sin 30} & B D=\sqrt{3} C D \\
\frac{B D}{1 / 2 \sqrt{3}}=\frac{C D}{1 / 2} &
\end{array}
$$

Figure 3. Examples of student work that shows a reading error

\subsection{Analysis for Comprehension Error}

There is an error of interpretation when the students read the queries, thus not recognizing the criteria and requirements. The $\mathrm{CE}$ most often occurs when students work on item 4 and decreases in number for items 3, 2, and 1 (Figure 2). The CE occurred because when reading questions, students misunderstand information, do not understand what is known and questioned, so they cannot work on the next process $[10,22]$. The cause of this error was confirmed in a dialogue with students (St.7) during the interview process.

Te : Why didn't you write about what already know in item test 2 ?

St.7 : Sorry, Sir. I'm confused when going to write notation of elements that are known in the work.

Te : What other parts do you find difficult?

St.7 : I don't understand putting a $30^{\circ}$ angle on the picture.

Te : What do you think was questioned in item 2 ?

St.7 : I think the distance between a starting point and endpoint.

Te : Why didn't you complete your work?

St.7 : There are some elements that are not yet known so I cannot continue.

The interview results and written tests show that students make errors in understanding the item test well indicated by not writing what is already known in the problem. This indicates that students do not understand the notation of known elements. In addition, students also misunderstood the meaning of turning $30^{\circ}$ to the south, so they misplaced the angle in the picture [23]. Based on interviews with St7, it can be clearly shown that students make mistakes in understanding the problem because they do not know the meaning of the sentence in the problem. This type of error can be seen in student work on item test 2 as shown in Figure 4.

2. Given that:

Asked: the existing ship distance with the position when the ship first departed

Solution:

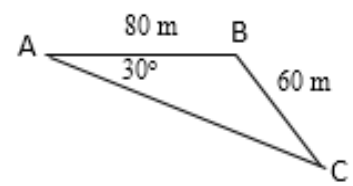

$$
\begin{aligned}
& A C^{2}=A B^{2}+B C^{2}-2 A B B C \operatorname{Cos} \angle A B C \\
& A C^{2}=80^{2}+60^{2}-2.80 \cdot 60 \cdot \operatorname{Cos} \angle A B C \\
& A C^{2}=6400^{2}+3600^{2}-9600 \cdot \operatorname{Cos} \angle A B C \\
& A C^{2}=10000-9600 \cdot \operatorname{Cos} \angle A B C \\
& A C^{2}=
\end{aligned}
$$

Figure 4. Student work that shows the occurrence of misunderstanding

\subsection{Analysis for Transformation Error}

There is a TE whenever students know the requirements of the problem already but cannot remember the trigonometry operations concerned. The TE distribution is almost evenly distributed on each item as shown in Figure 2. This error occurs for students not being able to transform problems into mathematical models and is also incorrect in using signs on arithmetic operations. This error type is usually caused by the carelessness of students in working on the problems being tested [10]. The following are the results of researchers' interviews with students (St.18):

Te : Why is the answer to your work on question number 3 negative?

St.18 : I was wrong in writing the formula, ma'am.

Te : Which part do you think is wrong?

St.18 : In the Cosine formula, it should be negative, but I wrote it positive.

$\mathrm{Te} \quad$ : Why is the formula you wrote wrong?

St.18 : I have difficulty memorizing various trigonometric formulas.

$\mathrm{Te} \quad$ : Are there any other causes?

St.18 : I think I didn't practice enough to work on problems so I rarely use the formulas that have been taught.

According to the written tests review and interviews with students S18, the student's work on question number 
3 can be shown to be inaccurate, caused by a student's mistake in writing the formula so that the mathematical model is incorrect. Actually, students know that the formula that is suitable for working on problems is the Cosine rule formula, but students make mistakes in writing. The formula written by students is $\mathrm{AD}^{2}=\mathrm{AB}^{2}+$ $\mathrm{BD}^{2}+2 \mathrm{AB} \cdot \mathrm{BD} \cdot \mathrm{Cos} \mathrm{B}$ even though the correct formula is $\mathrm{AD}^{2}=\mathrm{AB}^{2}+\mathrm{BD}^{2}-2 \mathrm{AB} \cdot \mathrm{BD}$. CosB. Examples of the work of students doing transformation error can be shown in Figure 5.

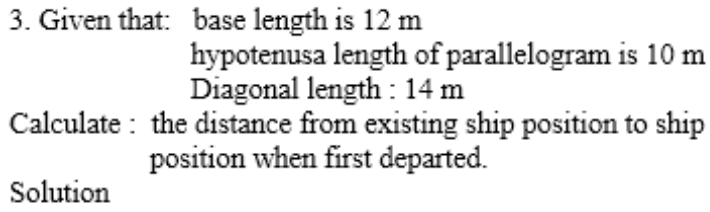

3. Given that: base length is $12 \mathrm{~m}$ hypotenusa length of parallelogram is $10 \mathrm{~m}$ Diagonal length : $14 \mathrm{~m}$

Calculate : the distance from existing ship position to ship position when first departed.

Solution

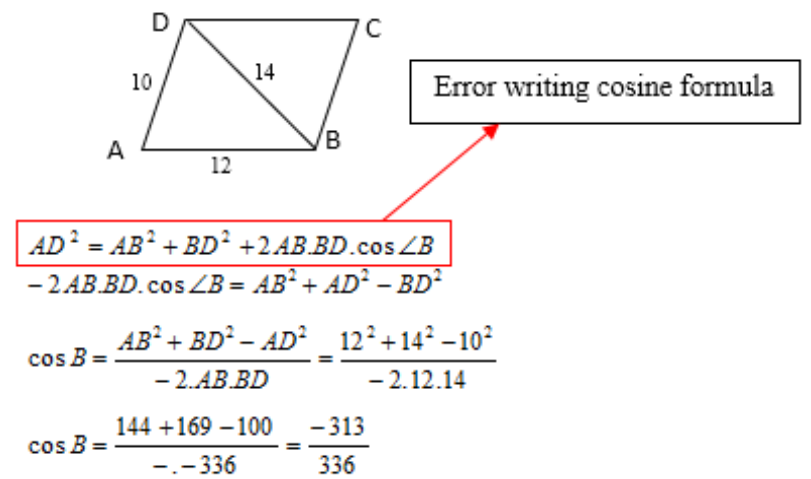

Figure 5. Examples of transformation errors by students in answering questions

\subsection{Analysis for Process Skill Error}

Errors in process skills are characterized by students' inappropriateness in undertaking the required process procedures. The PSE type errors are contributed by student work in item 4 (Figure 2). Examination on the student worksheet found that errors in calculations resulted in students unable to answer questions completely. This phenomenon has also been reported by several previous studies [24,25]. This type of error occurs due to the inaccuracy of students in the answering process and also their lack of understanding in fraction operations as confirmed in interviews with students (St.9).

Te : Do you understand how to solve problem number 1?

St.9 : Yes, I understand. It is drawn first and then done using the sine rules formula.

Te : Do you know where your work is at fault?

St.9 : Yes, of course. I was wrong in calculating fractions and roots.

Te : Why did you make a mistake?

St.9 : Because I am not very thorough and also in a hurry in working on the problems.

This interview confirmed the results of the written test (Figure 6) that students' work errors resulted from errors in calculating fraction procedures even though they were able to correctly interpret and be conscious of the questions [26,10]. For example, in Figure 6, it appears that students are wrong in carrying out the calculation procedure for fractions, where four divided by half should be eight instead of two, so the final result obtained is wrong.

\section{Given that: Distance $\mathrm{SD}=8 \mathrm{~m}$ $\angle S M D=45^{\circ}$ $\angle S D M=60^{\circ}$}

Find length of SM Solution :

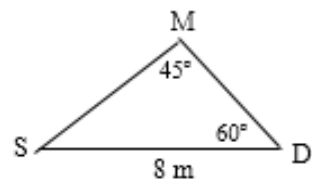

$$
\begin{aligned}
& \frac{\mathrm{SD}}{\operatorname{Sin} \angle \mathrm{SMD}}=\frac{\mathrm{SM}}{\operatorname{Sin} \angle \mathrm{SDM}} \\
& \frac{8}{\operatorname{Sin} 45^{\circ}}=\frac{S D}{\sin 60^{\circ}} \text { so that } \frac{\mathrm{SM}}{\frac{1}{2} \sqrt{3}}=\frac{8}{1 / 2 \sqrt{2}} \\
& \qquad M=\frac{1 / 2 \sqrt{3} \cdot 8}{1 / 2 \sqrt{2}}=\frac{4 \sqrt{3}}{1 / 2 \sqrt{2}} \\
& S M=\frac{2 \sqrt{3}}{\sqrt{2}} x \frac{\sqrt{2}}{\sqrt{2}}=\frac{2}{2} \sqrt{6}=\sqrt{6} \\
& \text { So length of } \mathrm{SM}=\sqrt{6} \mathrm{~m} \quad \begin{array}{l}
\text { Errors in calculating } \\
\text { fraction procedures }
\end{array}
\end{aligned}
$$

Figure 6. Examples of student work included in process skill errors

\subsection{Analysis for Encoding Error}

The category of encoding errors occurred in $27.39 \%$ of students indicated by their inability to conclude the answers so they could not write the final answers as requested. This error can also occur due to carelessness and lack of student accuracy in working on problems $[27,28]$ as shown in the following interview with students (St.23).

Te . Are you having trouble solving problem

St.23 : Oh no, I can do it according to the question about

Te Good, what formula do you use to solve problems?

St.23 : Formula for sine rules, Mrs.

Te : Did you make mistakes in writing formulas or calculations?

St.23 : No,

Te : What mistakes have made your score not optimal?

St.23 I I did not write the final answer according to the question, only wrote the results of 


\section{the calculation}

Te : Why did you do that?

St.23: I am less thorough and in a hurry in
solving problems, Mrs

This interview shows that the formula and stages of working on the problems are correct and in accordance with the demands of the questions, but students do not write the final answers as requested by the questions. From the written questions it is known that what is asked is the distance from the top of the pole to the students. The students have shown good understanding as indicated by the correct sketches, the appropriate sine rules formula, and the right calculation results. However, students do not write the conclusions of the answers made. Students should write the conclusion that the distance between the peaks to students is 2 meters, not just write 2 (black circle in Figure 7). This happens because students are less thorough and rushed in solving problems as informed in the interview.

$$
\begin{aligned}
& \text { 4. Given that : - distance from Ali to the pole is } 1 \mathrm{~m} \\
& \text { - distance from Irfan to the pole is } 1 \mathrm{~m} \\
& \text { - the depression angle between the top of } \\
& \text { the flagpole and the student's shoe is } 30^{\circ} \\
& \text { Calculate : Distance from top of flagpole to student } \\
& \text { Solution : Jika posisi Ali misalkan (A), Irfan (B), } \\
& \text { puncak (C) dan pangkal tiang (D) } \\
& \angle B C D=\angle A C D=30 \text { so } \angle A C B=60^{\circ} \\
& \angle C A B=\frac{180-60}{2}=60^{\circ} \\
& \frac{C B}{\operatorname{Sin} \angle C A B}=\frac{A B}{\operatorname{Sin} \angle A C B}=\frac{C B}{\operatorname{Sin} 60}=\frac{A B}{\operatorname{Sin} 60} \\
& \frac{C B}{1 / 2 \sqrt{3}}=\frac{2}{1 / 2 \sqrt{3}} \\
& C B=\frac{2 \cdot \frac{1}{2} \sqrt{5}}{\frac{1}{1 / 2} \sqrt{3}}=2
\end{aligned}
$$

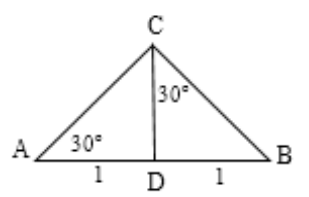

Figure 7. Student work that shows the occurrence of encoding errors

\section{Discussion}

Newman's error analysis at various student levels performance is shown in Figure 8 which presents the number of errors on each test item. The errors distribution shown in Figure 8 is $31.81,47.86$ and 20.32 percent for low, medium and high levels of achievement, respectively. In item 1, the most errors committed were in the high ability level for encoding with a percentage of $1.33 \%$. At the medium level, the most errors appeared in the encoding type of $3.68 \%$, while at the low level the most errors were found in the process skill and encoding types with a total percentage of $1.77 \%$. In item 2 , the most errors that appear at high levels are in the transformation type $(1.77 \%)$, while at medium levels, the most errors are in the encoding type $(4.27 \%)$. At low levels, the most errors were in the transformation type and process skill $(1.77 \%)$. Item 3 , errors at the high level mostly lie in the transformation and encoding types with a total percentage of $1.33 \%$, at the medium level the most errors are in the process skill type $(3.09 \%)$, and at the low level, the most errors are in the encoding type $(2.21 \%)$. For item 4 , the error at the highest level was the process skill type $(2.36 \%)$, errors at the moderate level were in the process skill type $(3.97 \%)$, while the errors at the low level were in the process skill and encoding types $(2.50 \%)$.

The students community with a medium degree of accomplishment was seen to be the most dominant in making errors. This is an exception because in the lowest level of accomplishment, response errors commonly occur. Although all types of errors occur, the type of reading error (RE) is the least common in students at the level of student achievement. The type of process skill error (PSE) for test item 4 on all achievement levels is the most common occurrence.

Trigonometry which function development is based on several concepts of analysis is an inseparable part of Mathematics. Errors in solving mathematical problems often occur both in writing and speaking [29]. In senior high school, trigonometry about the ratio between the edges of a right triangle, the ratio of sines, cosines, and tangents is taught only at specific angles and not in detail. This condition is closely related to the traditional methodology (procedural approach) which discusses concepts briefly so students often experience misunderstandings about new concepts [30]. The use of conceptual approaches to teaching trigonometry is a better choice than traditional approaches as suggested by Thompson et al. [31]. In the conceptual approach, students are emphasized to learn important concepts of mathematical connections and their applications [30,32] so that mistakes made by students due to misconceptions can be avoided.

Agoestanto et al. [33] have reported that students with weak cognitive abilities tend to create all errors types except in reading. The abilities of change analysis are not perfected in the understanding phase. Likewise, most learners struggle to turn problems into mathematical modeling at the stage of transformation. While transformational abilities are not mastered in the process ability level, which is demonstrated by the inability of students to convert the equation into another equivalent equation so that the correct equation solution is found. At the encoding stage, the skill of concluding is not mastered as indicated by the misinterpretation of the final solution [34]. Students who have independent cognitive abilities are more critical in thinking and make fewer mistakes [34]. Students of this sort, however, frequently make errors in aspects of theories and analysis of data in critical thinking skills. 


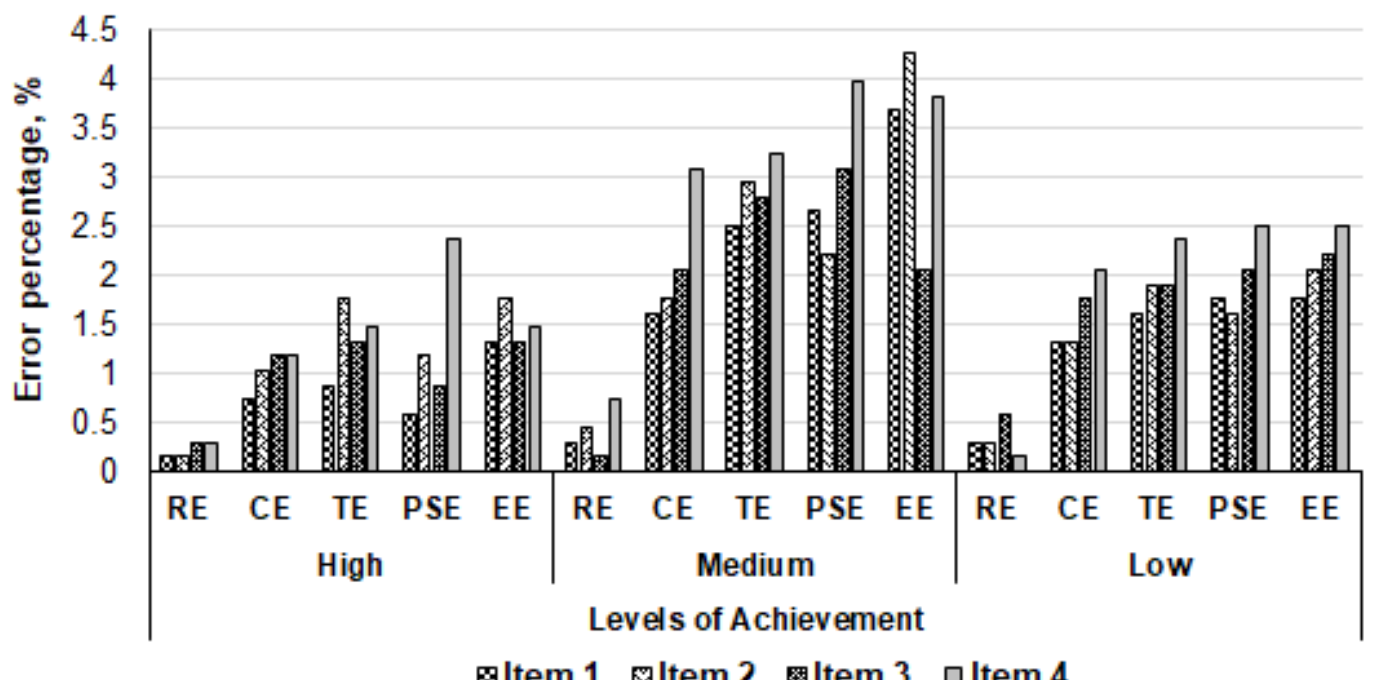

Figure 8. The number of errors against the level of achievement of each test item on various types of errors

\section{Conclusions}

Investigation of errors made by students in working on trigonometric problems in the application of sine and cosine rules has been carried out. Errors have been found and spread on all types of errors. The lowest to highest error levels are reading errors, comprehension errors, transformation errors, process skill errors, and encoding errors, respectively. Based on the classification of Newman's error theory, it was found that a total of 679 student errors were found. These errors spread to all types of errors. Of the 63 students who took the problem solving test, $22.98 \%$ of errors were found due to fluency (reading and understanding), while the errors caused by mathematical processing errors (transformation, skill processing and encoding) were $77.02 \%$. From written tests and interviews with students who make mistakes, it can be concluded that the sine and cosine rules are still felt difficult by many students as indicated by the high errors with relatively even distribution on all test items. Therefore it is very important for teachers to be creative and innovative in organizing learning on this trigonometric topic. All parties involved in learning must work together to eliminate students' assumptions that mathematics, especially trigonometry, is a difficult and scary topic. The learning situation is also very important to be pleasant so that it can make students enjoy the learning process.

This result is very important in determining future learning strategies, especially for students who have similar learning behaviors. Some recommendations should be evaluated on the basis of the findings of this study, which is that the idea of trigonometry can indeed be implemented in daily life so that students can better perceive trigonometric applications and also be independent to solve problems which will be fixed by themselves. Future studies have been planned to focus on the investigation of learning models and behavior towards student learning outcomes in trigonometry.

\section{Acknowledgements}

The author's thanks are extended to Dr. Eny Winaryati for the kindly suggestion and Mr. A. Solikhan for comments that greatly improved this paper. We would also like to show sincere gratitude to Professor Masrukhi for sharing his pearls of wisdom during this work.

\section{REFERENCES}

[1] P. Phonapichat, S. Wongwanich, S. Sujiva. An Analysis of elementary school students' difficulties in mathematical problem solving, Procedia - social and behavioral sciences, Vol. 116, 3169-3174, 2014.

[2] P. Liljedahl, M. Santos-Trigo, U. Malaspina, R. Bruder. Problem Solving in Mathematics Education. In: Problem Solving in Mathematics Education. Topical Surveys. Springer, Cham, 1-39, 2016

[3] L. S. Fuchs, S. R. Powell, P. T. Cirino, R. F. Schumacher, S. Marrin, C. L. Hamlett, D. L. Fuchs, Compton, C. Paul. Changas does calculation or word-problem instruction provide a stronger route to pre-algebraic knowledge? Journal of educational psychology, Vol. 106, No. 4, 990-1006, 2014

[4] K. Weber. Students' understanding of trigonometric functions. Mathematics education research journal, Vol. 17, No. 3, 91-112, 2005

[5] A. Sarac, F. A. Tutak. The relationship between teacher efficacy, and students' trigonometry self-efficacy and achievement. International journal for mathematics teaching and learning, Vol. 18, No. 1, 66-83, 2017

[6] Z. Ernaningsih, B. Wicasari. Analysis of mathematical 
representation, communication and connection in trigonometry. In: The 2017 international conference on research in education, 45-57, 2017

[7] V. May, S. Courtney. Developing meaning in trigonometry. Illinois mathematics Teacher, Vol. 63, No. 1, 25-33, 2016W. Zabierowski, A. Napieralski. Chords classification in tonal music, Journal of Environment Studies, Vol.10, No.5, 50-53.

[8] A. Delice. Recognizing, recalling and doing in the simplification of trigonometric expressions. The 26th Annual Conference of the International Group for the Psychology of Mathematics Education (PME26), the School of Education and Professional Development at the University of East Anglia, Norwich: England, 1, 247, 2002

[9] N. Orhun. The effects of learning styles on high school students' achievement on a mathematics course. Educational research and reviews, Vol. 8, No. 14, 1158-1165, 2013

[10] N. Orhun. Students' mistakes and misconceptions on teaching of trigonometry. 1st Ed. Web. 14 Jan. 2015.

[11] M. H. Usman, M. M. Hussaini. Analysis of students' error in learning of trigonometry among senior secondary school students in Zaria Metropolis, Nigeria. IOSR Journal of mathematics, Vol. 13, No. 2, 1-4, 2017

[12] E. Martín-Fernández, J. F. Ruiz-Hidalgo, L. Rico. Meaning and Understanding of School Mathematical Concepts by Secondary Students: The Study of Sine and Cosine, Eurasia journal of mathematics, science and technology education, Vol. 15, No. 12, em1782, 2019

[13] A. S. Brown, A.S. The trigonometric connection: students' understanding of sine and cosine. Proceedings 30th Conference of the International Group for the Psychology of Mathematics Education, 1, 228. Prague: PME30, 2006

[14] Armiati, Yerizon, R.O. Hersika. Trigonometry learning device based guided discovery for high school students of class X, International journal of scientific \& technology research, Vol. 8, No. 08, 31-37, 2019

[15] K. Hernawati, H. W. Surjono. Improving trigonometry learning motivation using Geogebra-Assisted Guided Discovery Student Worksheet (GDSW), Journal of Physics: Conference Series, 1320: 012082, 2019

[16] D. Sulistyaningsih, V. D. Mawarsari, I. Hidayah, Dwijanto. Manipulatives implementation for supporting learning of mathematics for prospective teachers. Journal of Physics: Conference Series, Vol. 824, No. 1, 1-5, 2017

[17] G. Polya. How to solve it, Princeton University Press, New Jersey, 1973

[18] J. W. Creswell. Research design: qualitative, quantitative, and mixed methods approaches. Third edition, Sage Publications, Thousand Oaks, Calif, 2009

[19] M. A. Newman. An analysis of 6th grade pupils' errors on written mathematical task. In M.A. Clements, J. Foster (eds). Research in Mathematical Education in Australia: 239258, 1997

[20] H. A. Elsa, E. Sudihartinih. Error Analysis of High School Students on Linear Program Topics Based on Newman Error
Analysis, Mathematics Education Journals, Vol. 4, No. 1, 7 16,2020

[21] C. Chusnul, Mardiyana, R. S. Dewi. Errors analysis of problem solving using the Newman stage after applying cooperative learning of TTW Type, AIP Conference proceedings, 1913, 020028, 2017

[22] S. K. Selling. Learning to represent, representing to learn. Journal of mathematical behavior, Vol. 41, 191-209, 2016

[23] S. W. Siyepu. Analysis of errors in derivatives of trigonometric functions. International journal of STEM education, Vol. 2, 1-16, 2015

[24] N. Agustyaningrum, A. M. Abadi, R. N. Sari, A. Mahmudi. An analysis of students' error in solving abstract algebra tasks. Journal of physics: conference series, 1097: 012118, 2018

[25] D. Fahrudin, Merdiyana, I. Pramudya. Profile of students' errors in trigonometry equations, Journal of Physics Conference Series, 1188: 012044, 2019

[26] A. H. Abdullah, N. L. Z. Abidin, M. Ali. Analysis of students' errors in solving Higher Order Thinking Skills (HOTS) problems for the topic of fraction, Asian social science, Vol. 11, No. 21, 133-142, 2015

[27] F. S. Mensah. Ghanaian senior high school students' error in learning of trigonometry. International journal of environmental and science education, Vol. 12, No. 8, 1709-1717, 2017

[28] H. Ahmad, Febryanti, Muthmainnah, A. Yakin, S. Sarbi. The analysis of student error in solve the problem of spherical trigonometry application, Journal of physics: conference series, 1114: 012114, 2018

[29] E. Zakaria. Analysis of students' error in learning quadratic equations. International education studies, Vol. 3, No. 3, $105-110,2010$

[30] D. Peal. Approaches to teaching with mathematics. Connection, Vol. 1, No. 3, 1-12, 2010

[31] P. W. Thompson, B. Byerley, N. Hatfield. A conceptual approach to calculus made possible by technology, Computers in the schools, Vol. 30, No. 1-2, 124-147, 2013 Conference, House of Lviv Polytechnic National University, 19-23, 2008

[32] S. Maharani, T. Nusantara, A.R. As'ari, A. Qohar Analyticity and systematicity students of mathematics education on solving non-routine problems. Mathematics and Statistics, Vol. 7, No. 2, pp. 50 - 55, 2019. https://doi.org/10.13189/ms.2019.070204

[33] A. Agoestanto, Y. L. Sukestiyarno, Isnarto, Rochmad, M. D. Lestari. The position and causes of students errors in algebraic thinking based on cognitive style, International journal of instruction, Vol. 12, No. 1, 1431-1444, 2019

[34] A. Agoestanto, Y. L. Sukestiyarno, Rochmad. Analysis of mathematics critical thinking students in junior high school based on cognitive style. Journal of physics: conference series, 824:012052, 2017. 